\title{
Letra, melodia, arranjo: componentes em tensão em $O$ morro não tem vez de Antonio Carlos Jobim e Vinícius de Moraes
}

\author{
Silvio Augusto Merhy (UNIRIO, Rio de Janeiro, RJ) \\ simerhy@globo.com
}

\begin{abstract}
Resumo: 0 registro fonográfico tornou mais fácil pensar uma produção musical como documento, não apenas como objeto de apreciação estética. A gravação de canções populares permite prontamente decompor, recompor, analisar, destacar partes e pensá-las como objeto pertencente a uma rede social de amplitudes quase infinitas. Ocasionalmente, o modo como se combinam letra, melodia e arranjo faz brotar questões sobre a classificação dos gêneros. 0 arranjo musical, suporte sonoro da canção, pode colocar em tensão a combinação letra e música e até mesmo deslocar o sentido do conjunto. Algumas das gravações de 0 morro não tem vez de Tom Jobim e Vinícius de Moraes revelam contrastes e tensões que tornam uma questão permanente o que se classificou como Bossa Nova.

Palavras-chave: canção popular brasileira; samba; favelas cariocas; Bossa Nova; Tom Jobim; Vinícius de Moraes.
\end{abstract}

Lyrics, melody, arrangement: elements in tension in Favela by Antonio Carlos Jobim and Vinícius de Moraes

Abstract: Records have made easier to think over a musical issue as a document, not exclusively as an aesthetic object. Through song recordings it is possible to decompose, recompose, analyze, extract components, etc., and most of all consider them as belonging to a vast social net. Putting together lyrics, melody and arrangement poses the question of classifying genres. Musical arrangements, as a kind of song frame, can break apart the former sense of the combination lyrics/melody. Some recordings of 0 morro não tem vez by Tom Jobim and Vinicius de Moraes disclose contradictions and tensions in what is called Bossa Nova and make it a permanent question.

Keywords: Brazilian popular song; samba; slums in Rio de Janeiro; Bossa Nova; Tom Jobim;Vinícius de Moraes.

\begin{abstract}
1 - A fruição e a análise das canções populares Produzir música tem como principal finalidade proporcionar fruição e prazer aos ouvintes. Transformar música em objeto de análise caracteriza-se por ser atividade restrita a um grupo qualificado de pessoas. A audição critica é deixada de lado quando a fruição e o prazer prevalecem, pois implicam em uma atitude distraída que une música e ouvinte pelas sensações. Contudo, a análise e a crítica podem ser estimuladas pelo simples prazer de ouvir música. A determinação de isolá-lo da audição crítica nem sempre é necessária, como ocorre na apreciação musical, em que o gosto está sempre presente, enquanto que na análise isso nem sempre é possível. A análise musical aprofunda a apreciação e transforma todo o processo em objeto, envolvendo ao mesmo tempo produção, obra e fruição.
\end{abstract}

No caso especifico do analista, ele pode escolher se ouve pelo prazer puro e simples ou se o deixa de lado para empreender processo de exame, interpretação, reflexão, explicação, etc. A análise pretende isolar o objeto $\mathrm{e}$, de certa forma, distanciar o ouvinte, ele próprio transformado em um dos elementos da análise, junto com a fruição.

Quando submetidas ao exame dos estudiosos, surgem nas canções populares, logo ao primeiro olhar, tensões que não são percebidas na simples fruição e que agora, diante do analista, revelam desarmonias intensas entre seus componentes. Antes ocultas ao prazer distraído, as tensões agora surpreendem pela evidência. Os ouvintes muitas vezes nem se dão conta de que a produção de sentido sofre interferências com as desarmonias e desequilibrios que ocorrem na produção ou nas performances das canções, tanto nas gravações quanto nas apresentações em público.

0 conjunto letra - melodia é absorvido pelos consumidores com naturalidade, uma espécie de unidade orgâ- 
nica resultante da união perfeita entre a palavra e os intervalos musicais.

A análise, no entanto, é compelida a considerar que a unidade orgânica de tal conjunto - a canção - não passa na verdade de ideia naturalizada que não se sustenta frente às suas condições de produção. No nível mais imediato constata-se que letras de músicas podem ser criadas antes, durante ou depois da composição das melodias, podem ser agregadas, montadas, modificadas ou simplesmente encomendadas, mudando o sentido da música. Em âmbito mais amplo as canções se colocam numa rede de produção que ata o processo de criação às canções anteriores compostas pelo artista, ao sistema de reprodução das artes em que ele está inserido, aos seus compromissos profissionais, à manutenção da sua imagem junto aos pares, à critica, ao público, etc.

Revelar por completo a rede social de relações em que as canções populares estão inseridas não é, por certo, uma aspiração deste estudo, embora tal desejo assombre constantemente muitos dos pesquisadores que têm a Música como objeto. Mas há evidências de que a realidade das relações sociais ou da vida em grupo não pode ser simplesmente omitida ou ignorada, sem que se corram riscos de resultados insatisfatórios. Por isso consulta-se o modo de pensar e de pesquisar dos profissionais de Ciências Humanas e Sociais, na esperança de buscar auxílio para as explicações e análises.

A caracterização das práticas musicais, por exemplo, pode se tornar incompleta se, na descrição, o ambiente em que ocorre é desprezado.

É necessário que se descrevam os elementos característicos que estruturam o produto artístico considerando-se 0 seu impacto no mundo social. As funções dos elementos que estruturam a forma artística estão, de algum modo, conectados ao tipo de prática e ao perfil do grupo onde ela ocorre. A análise pode revelar como se dão estas conexões e que tensões elas podem criar.

\section{2 - Divisão geográfica e social da cidade}

A cidade do Rio de Janeiro, capital federal brasileira até 1959, tem sido vista, muitas vezes, como uma cidade partida, sendo o asfalto e a favela uma das metáforas mais eloquentes dessa divisão. A favela, modelo de urbanização caracterizado pela precariedade, é o ambiente urbano predominante no recorte montanhoso. A uma partilha que se apresenta visivel entre asfalto e favela (o morro constituiu-se como sinônimo de favela) correspondem outras divisões: em classes sociais, em qualidade de vida, em regiões geográficas (a cidade também é dividida em norte-sul), em universos culturais, nas estatísticas policiais. A gênese social e o impacto cultural dessa partilha se perpetuam como marca da geografia, de modo que a luta contra e em defesa das favelas já se consolidou numa história de décadas. E os valores, fruto da partilha, têm sido igualmente combatidos e defendidos.
Em alguns aspectos o ambiente do Rio expõe o marco da divisão urbana, revelando forte tensão entre grupos humanos. A divisão e a tensão são visíveis na arquitetura favela/bairro, no comportamento - violência/cortesia, na produção artística - música de concerto/música do morro. No caso da música a divisão mais óbvia se exemplifica no contraste entre o ambiente da música de concerto, centralizada na programação do Theatro Municipal do Rio de Janeiro, e o ambiente do samba, fenômeno tributário dos morros e das comunidades cariocas, onde se localizam as Escolas de Samba. Em alguns momentos, 0 contraste entre música de concerto e samba carnavalesco é percebido como realidade indisfarçável. Durante o período de carnaval, os ensaios do Bloco Cordão da Bola Preta podem ser ouvidos alegremente durante os intervalos dos concertos no Theatro Municipal, localizado exatamente em frente à sede do clube Bola Preta. Outro embate: a Sala Cecília Meireles, importante casa de concertos, está localizada no bairro da Lapa, tradicional reduto do samba e da boemia carioca. Hoje revitalizada, a Lapa concentra agenda significativa de shows de música popular, com sucesso de público garantido. 0 samba e o choro podem ser ouvidos até nas calçadas em frente à Sala.

As temporadas de ópera, concertos e ballets com grandes nomes internacionais e estrelas nacionais sempre fizeram parte da programação da música clássica no Rio. 0 público se interessa pelas assinaturas de temporadas onde os grandes nomes internacionais se somam às estrelas locais. ${ }^{1}$

A cultura do Samba tem sido noticiada desde o princípio do século com relatos sobre as rodas de samba, os desfiles carnavalescos e a formação das primeiras Escolas de Samba. 0 panteão de nomes do samba tem sido sistematicamente cultivado e reverenciado. ${ }^{2}$

$\mathrm{Na}$ cidade do Rio de Janeiro, a música de concerto e o samba não se limitam a constituir apenas opções de programa cultural, marcam comportamentos, modos de vida e até oposições sociais. A menção à temporada de ópera e às escolas de samba aponta para situações extremas, contudo outras situações revelam oposições mais dissimuladas e contrastes menos intensos entre os gêneros musicais. Alguns deles não carregam marcas tão óbvias de sua origem social. 0 samba 0 morro não tem vez de Tom Jobim e Vinícius de Moraes de 1963 (MARCONDES, 1977), em suas muitas versões, expressa os contrastes da cidade partida de forma menos explícita.

\section{3 - Modalidade de ocupação habitacional}

A ocupação dos morros é um dos problemas que se eternizaram e que se tornaram característicos do Rio de Janeiro. 0 descaso perdura no poder público e os moradores tiveram que se adaptar, criando condições de sobrevivência que se naturalizaram através da geografia da cidade, brindada por recorte montanhoso privilegiado. Morro e favela são usados como sinônimos, embora favelas tenham sido plantadas também em regiões planas. 
A gênese das favelas é explicada por diversas hipóteses. Uma das mais aceitas é a da expulsão dos moradores pobres, ocasionada pela execução do plano de saneamento e urbanização do Governo Rodrigues Alves (1902-1906). A construção das avenidas Central e Presidente Vargas levou a demolições e impediu que os moradores pobres permanecessem na região saneada. ${ }^{3}$

Julio César Pino, professor associado do Departamento de História da Kent State University, examinou, no artigo Sources on the history of favelas in Rio de Janeiro, fontes documentais que lhe permitiram balizar a ocupação ilegal de áreas no Rio de Janeiro desde 1898. 0 autor se queixa (PINO, 1997, p.112) de que o maior número de estudos foi conduzido por sociólogos estrangeiros, cientistas políticos e criminologistas, ressentindo-se da falta de estudos de história social que descrevam como as favelas foram construídas e quem são seus moradores.

PINO (1997, p.111) data 1940 como o marco de uma era explosiva no crescimento das favelas na capital federal. No estudo observa-se que a maioria das fontes citadas é da década de 60 do séc. $X X$, talvez porque, neste período, a preocupação da sociedade e das autoridades tenha se tornado mais aguda. Contudo, a situação das moradias ilegais se mantém até os dias de hoje. 0 artigo registra levantamento de 1991, produzido pelo Instituto de Planejamento do Rio de Janeiro (IPLANRio), mostrando a cidade ocupada por 661 favelas.

As comunidades que habitam as favelas e os bairros pobres dos subúrbios cariocas são estigmatizadas. As condições de urbanização dos morros atestam a ausência do poder público, que pode ser absoluta durante certos mandatos. Em alguns deles prevalece a ideia de transformar as favelas em bairros; em outros, a de transferir os moradores para condomínios especialmente projetados.

0 interventor Henrique Dodsworth (1937-1945), nomeado prefeito por Getúlio Vargas, pretendia construir Parques Proletários Provisórios, projeto político do governo federal. Talvez tenha sido o primeiro prefeito a planejar a transferência dos moradores das favelas para condomínios ou bairros.

A Praia do Pinto 4 era uma favela à beira da Lagoa Rodrigo de Freitas, plantada ao nível do mar, em uma das regiões mais nobres da cidade, conhecida hoje pelo mais alto índice de desenvolvimento humano. Em 1955 Dom Hélder Câmara, bispo de Recife e bispo auxiliar do Rio de Janeiro, lançou a Cruzada São Sebastião, condomínio construído no bairro vizinho do Leblon, para abrigar os moradores da favela Praia do Pinto. 0 condomínio existe até hoje encravado no bairro.

0 prefeito Carlos Lacerda (1961-1964) desenvolveu projeto semelhante de transferência compulsória dos moradores de todas as favelas da cidade. No projeto, objeto de grande polêmica, foram criados vários bairros nos subúrbios do Rio. Talvez tenha sido o momento em que mais moradores foram transferidos em toda história da cidade. A deputada Sandra Cavalcanti, encarregada da Secretaria de Serviços Sociais da Prefeitura, tem sido até hoje acusada de causar o despejo truculento dos moradores.

0 deslocamento gradual das favelas dos morros para os subúrbios ainda está na ordem do dia. Os estudos das demandas dirigidas pelos moradores das favelas ao poder público mostram deficiência na oferta de serviços como escolas, luz elétrica, redes de água e esgoto, gás encanado, telefone, correio, etc.

As soluções para os problemas de moradia no Rio de Janeiro têm sido encaminhadas por visões antagônicas: retirada (quase sempre truculenta) de moradores para condomínios especialmente destinados a esta população ou urbanização dos locais de ocupação.

Nos bairros pobres a presença da autoridade do Estado pode ser sentida, mesmo que de forma incipiente. Entretanto, nas favelas ela sempre se caracterizou pela ausência. A ideia de transformar as favelas em bairros se assumiu como projeto governamental a partir de $1994 .^{5}$ A ideia de favela-bairro resulta da discussão de legalizar as favelas e tratar este modo de ocupação como modalidade não totalmente condenável.

\section{4 - A favela como tema}

A ideia de "resgatar a cidadania" através de projetos culturais tem sido muito difundida nas duas últimas décadas. Variados projetos com variadas feições culturais surgem em todos as localidades brasileiras, inclusive por iniciativas governamentais. Nas favelas do Rio, alguns deles ficaram bem famosos, como o Grupo Cultural Afro reggae, ONG localizada no bairro de Vigário Geral. ${ }^{6}$

Outra ideia de promover a cidadania utiliza a defesa da cultura local, dos valores dos próprios moradores das "comunidades". Não só os intelectuais e o governo como os próprios moradores fazem essa defesa, usando o discurso da autenticidade para valorizar sua cultura. "Comunidades", termo que atualmente designa os grupos sociais que habitam favelas, têm surgido em muitas outras cidades brasileiras, não só no Rio. Mas é a marca simbólica das favelas e morros cariocas que mais fortemente tem repercutido na sociedade e ganhado visibilidade nos meios de comunicação.

0 samba, há tempos elevado por consenso a traço de identidade nacional, é historicamente associado à gente que vive nas favelas e nos morros cariocas. É um gênero musical exaltado como produto de prestígio para as "comunidades" e incensado como criação "autêntica" destes grupos.

"Morro", "favela", "barracão" aparecem em muitas letras de sambas e de outros gêneros de canções brasileiras. Em muitas situações a presença dessas palavras é percebida como proselitismo ou como retórica em defesa de determinados grupos sociais. Em certas canções elas têm o fito de propagar os valores éticos das "comunidades" e concorrer para elevar o mérito artístico das músicas. 
Canções populares com esses temas foram produzidas já nas primeiras décadas do século $\mathrm{XX}$, algumas os expuseram até nos títulos, como os sambas: Favela, de Roberto Martins e Valdemar Silva (lançado em 1936); Ave Maria no morro, de Herivelto Martins (lançado em 1942); Barracão de Luis Antonio e Oldemar Magalhães, (samba carnavalesco lançado em 1953).7 Alguns deles são tocados ainda hoje, outros já estão esquecidos. É possivel compor lista numerosa, com canções de gêneros variados sobre o mesmo tema.

No início dos anos 60, nos ambientes onde as canções populares eram produzidas, o tema da ocupação ilegal para moradia transbordou das letras de canções e ganhou tons de radicalização e de conflito público de ideias entre os compositores e cantores.

\section{5 - 0 samba 0 morro não tem vez e a escolha das gravações}

0 samba 0 morro não tem vez de Antonio Carlos Jobim e Vinícius de Moraes se destaca na numerosa lista sobre o tema por características que variam de gravação para gravação. Selecionamos algumas das que podem evidenciar as diferentes concepções e as contradições que colocam em questão a coesão da própria criação. 0 samba tem sido gravado e regravado em diferentes épocas e em diferentes situações. Ao ser examinada de perto, a história de suas gravações mostra que o seu sentido sofre mudanças e se transforma sensivelmente.

0 jornalista Sérgio CABRAL (1997, p.497) listou trinta e oito (38) lançamentos diferentes de 0 morro não tem vez. Examinamos aqui apenas seis deles, entre 1963 e 2004. A escolha recaiu sobre gravações que apresentam fortes contrastes. Há contrastes no perfil dos artistas de capa, na concepção e estilo dos arranjos, nas condições de gravação, no lançamento e consumo da canção. Duas das gravações examinadas, as dos Cds do BR6 (2003) e do Garrafieira (2004), não aparecem na lista de Sérgio porque foram feitas após a edição do seu livro. Garrafieira e BR6 são grupos musicais formados por músicos cariocas jovens, mas experientes. 0 Garrafieira nasceu com a marca de ser predominantemente instrumental e o BR6 exclusivamente vocal. Os integrantes do BR6 contam que o grupo nasceu sob a inspiração do conjunto vocal americano Take 6.

0 cantor Jair Rodrigues incluiu 0 morro não tem vez como faixa do Lp 0 samba como ele é; Elis Regina incluiu-a no pot-pourri final do Lp No fino da bossa - ao vivo - vol.1 (Agostinho dos Santos canta 0 morro de Tom Jobim e Billy Blanco de 1955 [MARCONDES, 1977] na mesma faixa); Antonio Carlos Jobim estreou como cantor na faixa Favela incluida no Lp The Wonderful World of Antonio Carlos Jobim, com Nelson Riddle e sua orquestra; o próprio compositor criou para Favela belo solo de piano no Lp Antonio Carlos Jobim, the composer of Desafinado plays, gravado e distribuído nos Estados Unidos e reeditado no Brasil pela Elenco com o título de Antonio Carlos Jobim; no Cd BR6 o samba aparece como um dos vocais do grupo; no $\mathrm{Cd}$ Garrafieira ele surge na voz de Mariana Bernardes.

A letra do samba é um dos aspetos importantes da análise:

\author{
0 morro não tem vez \\ e o que ele fez já foi demais \\ Mas olhem bem vocês \\ Quando derem vez ao morro \\ Toda a cidade vai cantar \\ Morro pede passagem \\ Morro quer se mostrar \\ Abram alas pro morro \\ Tamborim vai falar \\ É um é dois é três é cem é mil a batucar \\ 0 morro não tem vez \\ Mas se derem vez ao morro \\ Toda a cidade vai cantar
}

\section{6 - 0 poeta autor da letra}

A letra do samba é o elemento que, através da voz dos artistas, permanece inalterado em todos os registros. 0 autor da letra de 0 morro não tem vez, o poeta Vinícius de Moraes, não se envolveu com a canção popular brasileira da mesma maneira que Tom Jobim. Envolveu-se também intensamente, mas atuou de forma diferente. A peça Orfeu da Conceição, escrita por Vinícius, manifesta de forma explícita a defesa cultural dos valores das comunidades do Rio de Janeiro. A associação da etnia às favelas e ao samba permanece ainda hoje no nosso imaginário de modo muito semelhante ao que ele concebeu.

A criação e a produção de Orfeu da Conceição, encenada por atores negros, marcaram um episódio notável na biografia de Vinicius. 0 próprio poeta descreveu como nasceu a ideia da peça, quando se sentiu "particularmente impregnado pelo espírito da raça", ${ }^{8}$ quando guiava um amigo, 0 escritor americano Waldo Frank, em visita à favela da Praia do Pinto. ${ }^{9}$ Os ritos de macumbas nas favelas, assistidos por ele, tinham algo a ver com a Grécia clássica. Sua intenção foi então prestar uma "homenagem ao negro brasileiro". 0 texto foi entendido como uma elevação dos dramas da população negra do Rio de Janeiro à condição de "universalidade". Além de uma carreira teatral de sucesso, tornou-se argumento da produção cinematográfica francesa L'Orfée nègre, filme premiadíssimo de Marcel Camus lançado no Brasil com o título de Orfeu do Carnaval. ${ }^{10}$ A montagem da peça reuniu os nomes dos artistas mais importantes na época, como Oscar Niemeyer para a cenografia e Tom Jobim para a música. A universalidade do drama foi enfatizada pelo teatrólogo Guilherme Figueiredo no programa da peça, que associa Orfeu, o músico grego, ao carioca da Conceição, o músico do morro.

\section{7 - A canção transfigurada}

O morro não tem vez não faz parte do Lp Músicas do Orfeu da Conceição, ${ }^{11}$ mas tem a mesma fonte de inspiração, apesar de ter surgido bem depois.

A primeira gravação foi feita em 1963, na voz de Jair Rodrigues, paulista do interior que chegou a São Paulo durante a década de 1950 . 0 cantor ganhou fama nos anos 60 , no 
apogeu da Bossa Nova e seu maior sucesso, Deixa isto pra lá, lançado em 1964, é considerado o primeiro rap brasileiro. 0 morro não tem vez é faixa do Lp 0 samba como ele $e_{1}^{12}$ ao lado de $O$ que se leva desta vida de Pedro Caetano, Meu fraco é mulher de Heitor de Barros e Conde e Feio não é bonito de Gianfrancesco Guarnieri e Carlos Lyra. O morro não tem vez de Tom Jobim e Vinicius de Moraes é a oitava faixa. 0 arranjo desta gravação é, dentre os comentados, 0 único que não chama a atenção para a harmonia. Lembra os arranjos estilizados dos programas de auditório das Rádios, com vocal feminino e naipe de metais. A introdução com cavaquinho pretende mostrar que a origem do samba está nos morros cariocas e continua na Zona Norte da cidade. Não há cavaquinho na Bossa Nova.

No registro de Jairo SEVERIANO e Zuza HOMEM DE MELLO (1998, v.2, p.70) o sucesso de Jair Rodrigues está listado no mesmo capítulo em que estão resenhados os mais famosos títulos criados por Tom Jobim e Vinicius de Moraes: Garota de Ipanema, Samba do avião, Só danço samba. 0 título do Lp 0 samba como ele é reivindica autenticidade (o samba como ele realmente é), e contém repertório constituído basicamente de canções compostas por compositores não originários da Zona Sul do Rio de Janeiro, sem nenhuma semelhança com os sambas lentos e intimistas. A maioria dos compositores que criaram os sambas lentos da Bossa Nova morava na Zona Sul da cidade ou circulava por ela. Tom Jobim, o compositor de maior prestígio, sempre habitou a Zona Sul. Jair Rodrigues e os compositores listados no seu Lp certamente não faziam parte deste grupo.

A sua participação no programa 0 fino da bossa, proporcionou-Ihe um público mais amplo. A dupla Jair/Elis gravou inicialmente o Lp Dois na Bossa, cujo sucesso resultou na criação do programa, estreado em maio de 1965 com grande e duradouro sucesso. Do programa surgiram três Lps intitulados No fino da bossa e comercializados até hoje. Em 2000, Jair voltou a reviver o clima extrovertido das gravações de 1965 e apresentou 0 morro não tem vez em show para reverenciar o Lp Dois na bossa.

0 pot-pourri ${ }^{13}$ final de No fino da bossa - ao vivo - vol.1, cantado por Elis Regina, Elza Soares, Lucio Alves e Agostinho dos Santos, foi gravado em 30/11/1965 e tem o "morro" como tema. A faixa reúne, além de 0 morro não tem vez, Despedida da Mangueira de Benedito Lacerda e Aldo Cabral, Zelão de Sérgio Ricardo e 0 morro de Tom Jobim e Billy Blanco. 0 samba-canção 0 morro, gêmeo musical de 0 morro não tem vez, é anterior e foi criado por Tom Jobim para a Sinfonia do Rio de Janeiro. ${ }^{14}$ É menos conhecido, mas faz também a defesa dos "valores do morro" não reconhecidos pelo "asfalto". Está presente no pot-pourri pela voz de Agostinho dos Santos, que se apresentou, junto com os demais, como convidado do programa 0 fino da bossa, da TV Record, liderado por Elis Regina e Jair Rodrigues, em parceria. 0 ambiente da gravação é de festa e alegria eufórica e não de protesto. A expressão vocal de Elis é cheia de bossa (o mote do programa), com trêmulos e outros recursos vocais, que por vezes soam exagerados ou inade- quados. Contudo o conjunto oficial do programa, o Zimbo Trio, ${ }^{15}$ saiu de cena substituído por um acompanhamento ao violão, o qual lembra o clima intimista da Bossa Nova, criando contrastes quando a euforia toma conta do grupo,

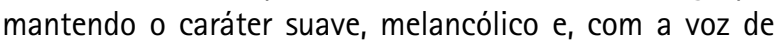
Agostinho dos Santos, bastante lento em 0 morro.

Elis Regina (1945-1982) mantém-se ainda hoje como o modelo mais almejado de cantora brasileira. Sua carreira artística é muito conhecida e muito difundida. Durante o período em que atuou no Fino da Bossa na TV Record predominou, na sua interpretação, o estilo extrovertido de cantar, com energia em excesso e muita movimentação de palco. 0 Zimbo Trio, que a acompanhou durante vários programas, também não se caracterizava por um estilo intimista ou jazzístico e se expressava no palco com muita intensidade, sem preocupação com sutilezas de dinâmica. Dez anos mais tarde, em Los Angeles, Elis gravou com Tom Jobim um dos discos mais famosos e reverenciados da MPB: o Elis e Tom (1974), tornado um ícone da Bossa Nova, por sua sonoridade contida, sutil e delicada em todas as faixas. 0 cuidado da produção, que transparece em todas as músicas, marca ainda mais o contraste entre o clima expansivo do programa ao vivo da TV Record e o disco de 1974.

No pot-pourri do Fino da Bossa, o tema do morro não parece ter sido escolhido como expressão de luta em defesa dos grupos sociais, dos moradores de favelas submetidos a condições de vida desfavoráveis. No entanto, reafirma 0 gosto pelo samba e mostra a sua força de comunicação na televisão, para um público mais diversificado e numeroso, não restrito à classe média moradora da Zona Sul do Rio. 0 samba de Elis, extrovertido, alegre e com muita bossa, não se assemelha ao ambiente das escolas de samba e dos compositores tradicionais dos morros do Rio. Sua atuação no auditório da Record não nos faz nem de longe pensar com indignação na situação dos favelados do morro.

0 Lp The Wonderful World of Antonio Carlos Jobim, com a voz de Tom Jobim e arranjos de Nelson Riddle, ${ }^{16}$ foi gravado e lançado nos Estados Unidos pela companhia Warner, tendo como artista de capa o compositor brasileiro. Tom assinou contrato com a gravadora e Nelson Riddle foi indicado para escrever os arranjos. Foi uma escolha ambiciosa, pois Riddle era um dos mais conhecidos arranjadores americanos, responsável pelos discos dos cantores e cantoras mais famosos dos Estados Unidos e do mundo. 0 arranjador era também conhecido no Brasil, em parte pelos fãs que compravam discos de Sinatra e de Nat King Cole. 0 morro não tem vez, cujo título foi traduzido para Favela, fez parte do repertório selecionado para o disco. A tradução literal para o inglês - Somewhere in the hills - está registrada na Ipanema Music Co, sociedade pertencente ao produtor americano Ray Gilbert e é mencionada por Sérgio CABRAL (1997, p.245). Mas o título escolhido para os dois discos produzidos nos Estados Unidos, Antonio Carlos Jobim, the composer of Desafinado plays e The Wonderful World of Antonio Carlos Jobim, foi mesmo Favela, abandonando-se 
Somewhere in the hills. É fácil entender que uma tradução literal poderia se afastar muito da ideia inicial de morro como sinônimo de favela e não como uma colina genérica, que em certas regiões é local de moradias de privilegiados e não de necessitados. 0 trabalho de Riddle foi recebido com restrições, mas se houve falhas não foi por desmerecer o "samba de morro", que jamais surgiria ali, mas por desentendimentos quanto à estética bossanovista que deveria predominar. Tom Jobim teria se queixado, mas concordou em cantar, deixando notar um certo constrangimento. Talvez a canção brasileira, imaginada por Riddle, tivesse semelhança com os modelos americanos de gravação dos grandes astros ou das canções românticas feitas para dançar. 0 que se ouve em Favela, no Lp The Wonderful World of Antonio Carlos Jobim, é um samba acompanhado por big band, escapando tanto da Bossa Nova quanto do "samba de morro". Só que escapar do "samba de morro" não parece ter contrariado ninguém.

0 Lp Antonio Carlos Jobim da Elenco, instrumental, com solo de piano de Tom Jobim e arranjos de Claus Ogerman, ${ }^{17}$ foi lançado em reedição no Brasil em 1964, um ano depois do elogiado lançamento da matriz americana com o título de Antonio Carlos Jobim, the composer of Desafinado plays. Um dos objetivos da reedição foi sem dúvida a sofisticação e a qualidade da produção, apreciada pelo próprio compositor. A sua insatisfação com Nelson Riddle $^{18}$ e a sua satisfação com o trabalho de Claus Ogerman revelam a face mais sofisticada da música brasileira, a face que, para muitos, a aproxima do jazz.

Tanto que, o resultado do Lp, também distante do "samba de morro", deixou a todos entusiasmados com o trabaIho do arranjador e com o estilo instrumental jazzístico que predomina no álbum. 0 próprio produtor, Aloysio de Oliveria, assinou a contracapa brasileira e Claus Ogerman tornou-se arranjador muito prestigiado por aqui, requisitado tanto por Tom Jobim como por João Gilberto. ${ }^{19}$

A letra brasileira de 0 morro não tem vez desapareceu na gravação e com ela sumiram as reivindicações. 0 estilo instrumental desautoriza pensar em qualquer conexão possível com os versos do samba. 0 título Favela permanece nos créditos, mas soa exótico e distante.Talvez o compromisso político de Tom Jobim com a luta contra as partilhas sociais injustas não fosse tão intensa quanto o do parceiro Vinícius, embora as relações profissionais e de amizade entre os dois o fossem. Considerando-se este dado, não teria sido dramático o abandono da letra na concepção do arranjo e da gravação americana de Claus Ogerman.

\section{8 - Os elementos de tensão não evidentes}

A ideia da "influência do jazz" surge quase sempre associada a um estilo harmônico determinado. Nas duas gravações de Favela, apresentadas com arranjos de Claus Ogerman e de Nelson Riddle, a harmonização mais simples é a de Claus Ogerman, que por ser instrumental, parece ao contrário bem mais jazzística do que a de Nelson Riddle, mais orquestral e harmonicamente mais elaborada. Nela se fundem o estilo jazzístico e a qualidade musical. A crítica muito elogiosa na review de Pete Welding, o autor do texto disponivel na contracapa de Antonio Carlos Jobim da Elenco, fala em "bossa nova movement". Pete WELDING (1963) afirma que

Este é o álbum mais 'curiosamente refrescante'. Curioso porque, durante todo o disco, Tom Jobim se apresenta como solista no estilo de one-finger piano. Refrescante porque é um dos álbuns mais cheios de lirismo, mais encantadores e deliciosos que resultaram da onda da bossa nova, a qual nos tem inundado no último ano. ${ }^{20}$

0 texto elogia apenas o Tom Jobim melodista e instrumentista. 0 songwriter Tom Jobim e o letrista Vinícius foram deixados de lado. One-finger piano é um elogio porque se refere ao despojamento da execução, cuja qualidade está no puro "feeling". Aloysio de Oliveira escreveu, na contracapa, um breve texto de apresentação para dar espaço à crítica da revista Downbeat, ${ }_{1}^{21}$ inserida no original e na íntegra.

A harmonização que se ouve nas gravações é um dos elementos que geram tensão, principalmente considerandose o proselitismo da letra. Esta afirmação não se aplica à gravação de Jair Rodrigues em que o elemento principal é a letra. Não há nenhuma menção ao jazz ou à Bossa Nova. 0 morro é o foco.

A harmonia utilizada nos discos Antonio Carlos Jobim da Elenco e No fino da bossa com Elis Regina ainda mantém a relação diatônica com a melodia como predominante, enquanto que nas outras gravações predominam a reelaboração e a rearmonização. A progressão harmônica Am7 Em7 em modo menor natural, que harmoniza o início do samba no Lp Antonio Carlos Jobim, não é comum nas canções brasileiras gravadas na mesma época ou em épocas anteriores, mas tampouco contém as dissonâncias acrescentadas nas rearmonizações. Se examinarmos $F a$ vela, de Roberto Martins e Valdemar Silva, Ave Maria no morro de Herivelto Martins e Barracão de Luis Antonio e Oldemar Magalhães veremos que o estilo harmônico é outro. A utilização do modo menor natural, que proporciona à melodia um sabor modal através do uso do $\mathrm{V}$ grau menor Em7, não fazia parte do vocabulário de acordes da maioria dos sambas. A harmonia inicial do pot-pourri de No fino da bossa acrescenta o acorde E7 produzindo dissonância de nona aumentada com a nota Sol da melodia.

A harmonização, aparentemente despretensiosa já proporciona, entretanto, um ambiente jazzístico na progressão do final da segunda parte F7(\#9) E7(\#9) D7(\#9), com a cadência em D7(\#9), IV grau do modo menor melódico com nota estranha ao acorde. A progressão final descrita aparece em todas as gravações, completamente incorporada à melodia.

Os arranjos posteriores seguiram alterando a harmonia. No disco The Wonderful World of Antonio Carlos Jobim a faixa Favela foi rearmonizada e sofisticou-se ainda mais. A harmonia inicial abandonou o modo menor natural, preferindo A7 Bb7 A7 Bb7, a mesma progressão escolhida pelo conjunto BR6. 0 grupo Garrafieira preferiu utilizar a harmonização A7 G7 A7 G7 A7 G7 A7(\#9) Dm7 G7(13) C\#m7 C7 F6 E7 Am7 Em7 Am7. É esta a harmonização escolhida para 
a transcrição apresentada na coleção de Almir Chediak Tom Jobim (JOBIM, [1990], v.1, p.89). Em todos os padrões descritos, a dominante E7 é pouco efetiva, porque a sensível Sol \# não é usada na melodia. 0 estilo predominante nas harmonizações tende a causar a impressão de que a harmonização "esqueceu" a retórica da letra, que profetiza que "Quando derem vez ao morro toda a cidade vai cantar". 0 contraste entre o estilo harmônico e a letra é evidente.

0 arranjo ao vivo para Elis Regina No fino da bossa parece ainda acreditar que o canto do morro vai descer para 0 asfalto. Já no arranjo de Nelson Riddle para The Wonderful World of Antonio Carlos Jobim não há nenhum tamborim e a percussão e os metais soam pesadamente sem nenhuma conexão com a letra. As cordas não lembram nem o samba nem o balanço da bossa. Teria a linha melódica predominado sobre a letra e absorvido toda a atenção do arranjador americano? Parece ser um divórcio que se acentua ainda mais na gravação do Lp Antonio Carlos Jobim ao piano. 0 solo de piano se ambienta em um espaço no qual a "comunidade" do morro, acompanhada por mil tamborins, jamais se sentiria em casa. 0 feeling é, sem dúvida, mais adequado aos clubes dançantes do que à paisagem das favelas. Há certamente quem possa pensar que a favela ganha "universalidade" quando inspira música capaz de sensibilizar pessoas tão distantes quanto um crítico exigente da revista Downbeat.

0 morro cantado pelo Garrafieira e pelo BR6 não causa espanto nem é desconcertante. Seguem o modelo de valorização da harmonia e das notas estranhas aos acordes. Embora haja semelhança quanto à valorização da harmonia e quanto ao gosto por acordes alterados, são gravações que reproduzem climas bastante distintos,

BR6 cultiva o gosto pelas alterações de maneira semelhante à que o grupo 0 s Cariocas o fez nos anos 50 e 60. A tradição dos grupos vocais na canção popular brasileira é tributária dos grupos americanos e de Os Cariocas. São as duas principais referências na elaboração dos arranjos vocais, mesmo quando se percebe o balanço da bossa aflorando na voz do solista Eduardo Braga e a batucada ilustrando no início da faixa a origem do samba. 0 arranjo de André Protásio mantém a tendência de valorização da harmonização com acordes alterados, desenvolvida pelos Cariocas e retomada pelo Garganta Profunda, grupo de grande prestígio nas últimas décadas, criado pelo regente Marcos Leite.

Os arranjos vocais têm destinação prévia específica. São direcionados desde a concepção para o grupo que vai cantá-los, de modo que o tipo de conjunto funciona como um dado previamente conhecido. Talvez por essa razão sejam menos autorais e mais instáveis ainda que os orquestrais.

Garrafieira se caracteriza por cultivar o samba urbano, sobretudo na forma instrumental, porém, apesar disso, convocou a cavaquinista e vocalista Mariana Bernardes para o solo vocal de 0 morro não tem vez. $0 \mathrm{Cd}$, que valoriza os instrumentistas, não dispensou a presença da letra de Vinícius de Moraes na faixa gravada. De todas as gravações já mencionadas, esta é a mais movimentada e animada, sendo tocada em andamento mais rápido que as demais e tendo o swing como elemento importante. 0 balanço apreciado na época em que se gravou No fino da bossa fez um longo percurso até o swing proposto pelo Garrafieira. Nas duas gravações, não só os arranjos são bem distintos, como a maneira de tocá-los também. A harmonia, bastante valorizada pelo Garrafieira, e o andamento mais rápido, imprimido pelos instrumentistas do grupo, garantem para o samba a possibilidade de ser ouvido de outra maneira.

Do ponto de vista dos ouvintes parece aceitável que uma harmonia bastante sofisticada possa sustentar poesia tão cheia de proselitismo. 0 gosto pela harmonia sofisticada está bastante difundido e permite, sem sobressaltos ou contrariedades, o seu casamento com a defesa dos ideais sociais.

\section{9 - Considerações sobre uma prática naturalizada}

A naturalização das categorias musicais ocorre como um processo constante. Algumas são construidas durante anos, outras durante décadas, sancionadas pelas estruturas políticas, culturais ou educacionais.

A letra é o elemento mais estável da canção. Sob este ponto de vista, é o componente mais importante, porque a identifica e restringe as possibilidades de adaptação ou modificação dos versos.

No entanto, é preciso assinalar que a sua conexão plena com a melodia e a harmonia pode ser questionada. Sabemos que o choro Carinhoso de Pixinguinha, criado em 1917 como peça instrumental, recebeu apenas em 1936 a letra de João de Barro que conhecemos. ${ }^{22}$ Muitos compositores oferecem suas músicas para poetas colocarem letras ou, em movimento oposto, compõem melodias para letras já existentes. Podemos fazer uma longa lista de situações semelhantes ou contrastantes com esta. Algumas canções estrangeiras tornam-se grandes sucessos e, depois de receberem a versão em português, são apropriadas pelo público como brasileiras. As versões em português são às vezes as únicas gravações conhecidas pelo público. A cantora Marisa Monte ficou famosa com o pop Bem que se quis do italiano Pino Daniele com versão de Nelson Motta, tocado na trilha sonora da novela da Rede Globo 0 salvador da pátria de 1989. 0 original italiano $E$ po che fà pouco se conhece.

0 que chama a atenção não são as situações eventuais, mas o fato de que, mesmo dispondo desta informação, mantemos como real a ideia de que a canção possui uma unidade orgânica de pertencimento recíproco: aquela letra pertence àquela canção e aquela canção àquela letra.

Na prática ocorre que a canção é criada entre percalços reais, que apagamos da memória em favor da ideia de uma unidade orgânica natural. Acionada, a ideia de organicidade ganha existência e age sobre a canção dando vida a um produto "pronto". 
A canção - unidade de melodia e letra - é resultado de naturalização tanto quanto o é o arranjo musical, cujas definições disponiveis ainda são insuficientes para dar conta de suas especificidades e para caracterizá-lo como prática distinta da criação musical e da composição.

Os arranjos musicais são de fato composições porque são criações, que, escritas ou não, corporificam o momento da produção musical. 0 ponto de vista que considera que o arranjador é um técnico coloca em risco a figura do artista criador, personagem social muito valorizado. Os produtos dos arranjadores ainda não se definiram como obras autorais porque só interessam aos instrumentistas que os executam, sendo sua função restrita a esse momento. São tratados como trabalho derivado e não como obras autorais autônomas, pois a dimensão autoral se esvai após a performance.

No momento da produção de um disco, o artista que se anuncia é o cantor e não o arranjador. É o cantor que dá nome ao disco, associado ao compositor das canções, a eles se atribui função autoral. Eles são os artistas e não 0 arranjador, transformado num colaborador a soldo.

0 arranjo interfere na produção da canção como obra de criação e tem força de significação para produzir sentido e modificar a própria canção. No entanto, se aceita com tranquilidade a sua condição de categoria técnica e de trabalho derivado, naturalização que afasta a possibilidade de inconformismo ou de luta efetiva pela condição de obra artística e por um lugar no âmbito da arte musical.

Nas gravações de 0 morro não tem vez os arranjos foram determinantes e interferem significativamente no sentido que se produz. A ênfase reiterada dos arranjos nas notas estranhas à harmonia diatônica não fez com que se deixasse a canção de lado, mas antes parece ter estimulado as regravações, que se renovam desde 1970. É a melhor comprovação de que a existência de contrastes e tensões entre elementos de uma mesma peça pode não causar estranheza nem se transformar em fator de rejeição. É possível a aceitação de grandes contrastes no perfil dos artistas de capa e na concepção e no estilo dos arranjos. Também são bem absorvidas as estratégias de gravação, divulgação e consumo, elementos que certamente determinam o tipo de produto que se quer distribuir.

Não há do que se queixar. 0 samba continua sendo gravado com sucesso e continua seduzindo músicos e ouvintes que desprezam todas as contradições e incongruências. Ele permite que os arranjadores ajam como compositores de fato.

Nem o próprio compositor, Tom Jobim, parece ter reclamado das transformações. Ao contrário, deve ter apreciado as harmonizações, pois a revisão dos songbooks, que contém rearmonizações da canção, passou, é claro, pelas suas mãos. A preocupação com a "preservação de valores autenticamente brasileiros", com a "música de raiz" e com a "identidade do samba" ainda não abalou o gosto por 0 morro não tem vez, nem sentenciou sua rejeição.

Se for escrita uma história da recepção das suas gravações talvez se revele mais claramente como estas lutas de representação se mantêm apaziguadas, pelo menos 0 suficiente para não perturbarem o prazer dos ouvintes.

\section{Referências}

CABRAL, Sérgio. Antônio Carlos Jobim. 2. ed. Rio de Janeiro: Lumiar, 1997.

CALDEIRA, Jorge (org). A história contada por quem viu. São Paulo: Mameluco, 2008.

CASTELLO, José. O poeta da paixão. Rio: Companhia das Letras, 1999.

JOBIM, Tom. Song book Tom Jobim. Org. Almir Chediak. S. Paulo: Lumiar, [1990]. 3 v.

MARCONDES, M.(org). Enciclopédia de Música Brasileira. S.Paulo: Arteditora, 1977. 2v.

PINO, Julio C. Sources on the history of favelas in Rio de Janeiro. Latin American Research Review, Vol. 32, No. 3 pp. 111-122.

Pittsburgh: The Latin American Studies Association, 1997.

SEVERIANO, Jairo e MELLO, Zuza Homem de. A canção no tempo. 2. ed. S. Paulo: Editora 34, 1998, 2 v.

WELDING, Pete. Antonio Carlos Jobim. Texto na contracapa do disco. Elenco ME-9, 1963. 


\section{Discografia}

BR6. BR6. Biscoito Fino, 2003.

GARRAFIEIRA. Garrafieira. Biscoito Fino, 2004.

JOBIM, Antonio Carlos. Antonio Carlos Jobim. Elenco ME-9, 1963.

Antonio Carlos Jobim, the composer of Desafinado plays. Verve, 1963.

The Wonderful World of Antonio Carlos Jobim. Warner WS 1611, [1965].

Antonio Carlos Jobim com Nelson Riddle e sua orquestra. Elenco MEV06, 1965.

REGINA, Elis. No fino da bossa - a o vivo - vol.1. Cd- Velas BR - 11-V030.V1, 1994.

RODRIGUES, Jair. 0 samba como ele é. Lp Philips (P 632.162 L), 1963.

500 anos de folia - vol.2. Trama T500/196-2. Cd, 2000.

\section{Notas}

10 Theatro Municipal do Rio de Janeiro informa no seu site que, no seu concerto de estreia, a Orquestra Sinfônica do Theatro teve como solista o tenor italiano Tito Schipa, sob a regência de Francisco Braga. 0 compromisso de temporadas de óperas, concertos e ballets que incluem artistas internacionais se formou desde o momento da inauguração do Theatro.

2 Paulo da Portela é personagem principal nas histórias do samba. Ele compõe verbete da Enciclopédia de Música Brasileira onde se descreve com muitas cores a sua participação nos desfiles carnavalescos e nas rodas de samba do subúrbio de Osvaldo Cruz.

3 Interessante a introdução e a reportagem sobre a revolta da vacina no livro organizado por Jorge CALDEIRA (2008, p.447).

4 A favela da Praia do Pinto teria inspirado Vinicius de Moraes a criar a peça Orfeu da Conceição. (c.f. nota 8)

5 Informações completas no site da Prefeitura da Cidade do Rio de Janeiro, que idealizou e executa o projeto favela-bairro. (www.rio.rj.gov.br/ habitat/favela_bairro.htm)

6 No site do Grupo Cultural aparecem os disticos "Música para combater a violência" e "Arte para transformar a realidade".

7 As datas estão todas indicadas no livro de Jairo Severiano e Zuza Homem de Mello.

8 A declaração aparece no programa da montagem de estreia da peça.

9 José CASTELLO (1999, p.125), seu biógrafo, descreve também a visita à favela.

100 cineasta francês Marcel Camus transpôs Orfeu da Conceição para o cinema com o título de L'Orphé Nègre e teve uma premiação triunfante em 1959, a Palma de Ouro em Cannes e o Oscar de melhor filme estrangeiro, representando a França. Foi uma excelente divulgação para a música de Tom e Vinícius e para a canção popular brasileira.

11 Long Play 10", Odeon MODB 3056, lançado em 1956

12 LP Philips P 632.162 L.

13 Pot-pourri é sinônimo de medley, termo mais usado hoje.

141954 é a data indicada por Sérgio Cabral para o disco Sinfonia do Rio de Janeiro, produzido pela gravadora Continental. (1997, p.514)

150 Zimbo Trio é um conjunto instrumental brasileiro surgido em 1964 e formado originalmente por Amilton Godoy ao piano, Luis Chaves no contrabaixo e Rubinho Barsotti na bateria.

16 Nelson Smock Riddle, Jr. (1921 - 1985) foi um conhecido bandleader americano, arranjador e orquestrador cuja carreira se expandiu a partir do final dos anos 40. Ele produziu arranjos para vários cantores como Frank Sinatra, Dean Martin, Nat King Cole, Judy Garland, Peggy Lee, Ella Fitzgerald, entre outros.

17 Claus Ogerman (1930 - ) é um músico de origem alemã, nascido na Prússia (hoje parte da Polônia). Arranjador, regente e compositor, trabalhou na Alemanha, depois se fixou nos Estados Unidos. Tornou-se muito conhecido no meio musical brasileiro ao compor arranjos para discos de Tom Jobim e de João Gilberto.

18 Sérgio Cabral conta que a expectativa de Tom Jobim foi frustrada. Ele não se entendeu musicalmente com o arranjador americano. (1997, p.242)

19 Ele fez os arranjos do LP Amoroso de João Gilberto.

20 "As the Schwepps man woud say, this is a most "curiosly refreshing" album. Curious, for during the entire length of the disc, Jobim, who is the featured soloist, plays what amounts to one-finger piano. Refreshing, because it is one of the loveliest and most deliciously lyrical albums to result from the bossa nova wave with which we've been inundated last year."

21 "O texto habitual de contracapa que aqui deixa de figurar, é substituido neste caso pela transcrição da critica de "DOWN BEAT", "a mais conceituada revista musical dos Estados Unidos, que considerou este disco um dos melhores da temporada, e que nós temos o privilégio de oferecer a você."

22 Severiano (1998, v.1, p.153-154) conta que o próprio Pixinguinha informou a data de 1917 como sendo o ano da composição. A peça instrumental teve muitas gravações, contudo após receber a letra em 1936 o número de gravações cresceu muito, sendo a primeira a de Orlando Silva em 1937.

Silvio Augusto Merhy é Bacharel em Direito pela UFRJ (1968), Bacharel em Piano pela UFRJ (1968), Mestre em Música pela UFRJ (1995) e Doutor em História Social pela UFRJ (2001). Atualmente, é Professor Associado II na UNIRIO. Atua no ensino de música principalmente com Harmonia de Teclado, Transcrição da Canção e História da Música Popular. Possui proficiência em russo, alemão, francês, inglês, espanhol e noções de grego. Ainda na UNIRIO, foi Diretor do Instituto Villa-Lobos e coordenador do Programa de Pós-Graduação em Música. 